\title{
NOTAS SOBRE A CONTRIBUIÇÃO DA OBRA DE MARIA HELENA SOUZA PATTO EM UM PROGRAMA DE PÓS-GRADUAÇÃO EM EDUCAÇÃO
}

\author{
Elizabete Bassani \\ Hiran Pinel
}

Resumo: O objetivo deste artigo é apresentar a trajetória de elaboração e implantação de uma disciplina oferecida, a partir do ano de 2009, pelo Programa de Pós-Graduação em Educação (PPGE) da Universidade Federal do Espírito Santo (UFES), intitulada "A Produção do Fracasso Escolar na Obra de Maria Helena Souza Patto" e relatar as contribuições dessa disciplina e da obra da autora na formação de professores e pesquisadores que têm como objeto de estudo o "fracasso escolar" em escolas públicas capixabas e brasileiras. Com esse propósito, apresentamos o contexto do PPGE, a configuração da disciplina oferecida e como a referida obra foi sendo desvelada para o grupo de alunos (mestrandos e doutorandos), assim como os desdobramentos da disciplina no PPGE.

Palavras-chave: Formação de professores. Fracasso escolar. Pós-graduação. Psicologia escolar.

A partir do desenvolvimento de um projeto de pesquisa/extensão iniciado em 2009, tendo como principal objetivo atender a uma escola pública municipal de Vitória-ES no que tange a orientação à queixa escolar, assim como produzir conhecimento acerca das concepções de fracasso escolar apresentadas por pedagogos, professores, pais e alunos e como essas concepções influenciam nos encaminhamentos dados aos alunos considerados "fracassados", criamos um gru- 
po de estudo objetivando buscar autores que contribuíssem com a compreensão do fenômeno estudado. $O$ projeto acima citado nos permitiu conhecer uma escola municipal que, a cada dia, nos levava a um reencontro com a obra de Maria Helena Souza Patto. Relatos de alunos, pais, professores, pedagogos pareciam ser um eco do que a autora havia revelado da realidade educacional brasileira na década de 1980 em seu livro A Produção do Fracasso Escolar. Essa experiência nos levou a compreender a atualidade dessa obra e a importância de resgatá-la no estudo da complexidade do problema fracasso escolar no município de Vitória em 2009.

A realidade apresentada na escola nos levou a perceber que em pleno século XXI, apesar de uma nova roupagem, o problema do "fracasso escolar" no contexto estudado repousa sobre questões que nos vêm sendo apresentadas pela autora há décadas. Essa experiência nos levou, em 2009, a oferecer uma disciplina no Programa de Pós-Graduação em Educação (PPGE), na Universidade Federal do Espírito Santo (UFES), com o objetivo de compreender o "fracasso escolar" a partir da obra de Maria Helena Souza Patto. Nosso objetivo, ao oferecer a disciplina, era resistir a um fantasma que insiste em bater a nossa porta. Um fantasma que parece trazer do passado concepções fisicalistas de homem e de sociedade e que, como nunca, impregnam o ambiente acadêmico e das escolas públicas capixabas.

Relatar a importância dessa disciplina e da obra de Maria Helena Souza Patto na formação de professores e pesquisadores que procuram entender o fenômeno do "fracasso escolar" no município de Vitória-ES será o objetivo deste artigo. Para isso, iremos brevemente apresentar o contexto do PPGE, da linha de pesquisa em que nosso projeto e a disciplina se desenvolvem, os objetivos e a configuração da disciplina e como a referida obra foi sendo desvelada para o grupo de alunos (mestrandos e doutorandos).

\section{O Programa de Pós-Graduação em Educação (PPGE)}

O Programa de Pós-Graduação em Educação (PPGE) da Universidade Federal do Espírito Santo (UFES), desde sua criação há 30 anos, vem desenvolvendo pesquisa sistemática referente à realidade educacional brasileira e sobre o estado do Espírito Santo, com o objetivo de produzir uma formação de alunos de mestrado e doutorado, para o exercício da docência em nível superior e da pesquisa científica, no campo da Educação.

Com a implantação, em 2004, do curso de doutorado, o programa pode desenvolver estudos ainda mais aprofundados sobre nossa realidade educacional e também, a partir de uma proposta de maior flexibili- 
zação de seu currículo, permitir sua permanente atualização e articulação com a realidade local, nacional e global, dando subsídios teóricometodológicos que possibilitem aos alunos construir conhecimento na área da Educação.

Inserido no Centro de Educação da UFES, está em permanente desenvolvimento de projetos de pesquisa e extensão que envolvem, além dos alunos de pós-graduação, alunos de graduação em Pedagogia e de diversos cursos de licenciatura. As linhas de pesquisa que compõem o PPGE, de acordo com seus objetivos, desenvolvem projetos em várias áreas e campos, gerando complexidade e riqueza em sua produção. Atualmente o programa está constituído a partir de quatro linhas de pesquisa; são elas: Linha 1:Cultura, currículo e formação de educadores; Linha 2: Diversidade e práticas educacionais inclusivas; Linha 3: Educação e linguagens; e Linha 4: História, sociedade, cultura e políticas educacionais.

Apesar de haver uma inter-relação entre as linhas apresentadas, aqui, devido ao objetivo de nosso artigo, iremos descrever a Linha Diversidade e Práticas Educacionais Inclusivas (em que está situada a disciplina apresentada neste artigo) para que possamos retratar mais especificamente a contribuição da obra da professora Maria Helena Souza Patto em pesquisas que vêm sendo desenvolvidas por professores e alunos ligados a essa linha, que atualmente conta com sete professores orientadores.

Seu principal propósito consiste em estudar a teoria e a constituição de sujeitos imersos nas práticas educativas escolares e não escolares inclusivas, considerando diferentes concepções de desenvolvimento e aprendizagem. Tem como objetos privilegiados: processos psicossociais constitutivos do sujeito; processos de ensino e aprendizagem; fundamentos histórico-filosóficos e políticas da educação especial; práticas organizativas e pedagógicas e formação de profissionais que se dedicam à educação de sujeitos com necessidades educativas especiais.

Foi com o propósito de atendermos aos objetivos da linha a que pertencemos que implantamos nosso projeto de pesquisa/extensão, intitulado "Labor-Psi: Avaliações, Acompanhamentos \& Diagnósticos - Intervenções Psicopedagógicas na Educação". Nesse projeto, a realidade apresentada pela escola onde desenvolvemos nossos estudos e intervenção foi produzindo, a cada dia, uma maior aproximação da obra de Maria Helena Souza Patto. A realidade que brevemente descreveremos abaixo nos impulsionou a elaborar e oferecer, em 2009/2, a disciplina intitulada "A Produção do Fracasso Escolar na Obra de Maria Helena Souza Patto", para alunos do PPGE.

Escolhemos essa obra como principal referencial teórico de nossa disciplina porque o contexto pesquisado passou a ser pensado por uma lógica em que o"fracasso escolar"é visto como denúncia de um sistema econômico e político perverso, que gera a necessidade de busca de com- 
preensão da instituição escolar. Maria Helena Souza Patto, em sua obra, abre as cortinas e desnuda a realidade da escola pesquisada na década de 1980, em um bairro de periferia de São Paulo. Percebemos que o cenário revelado desagrada e por isso algumas políticas, como as atuais, insistem em desenvolver projetos que mascaram a realidade. Por isso, nossa afirmação sobre a atualidade de sua obra que, a partir de décadas de construção, contribui mais do que nunca para a formação de professores e pesquisadores da área escolar, levando a uma compreensão do "fracasso escolar" em uma perspectiva em que a instituição escolar é pensada e em que não se culpabiliza a criança pelo "seu fracasso". Apesar do contexto social e político atual parecer muito diferente do estudado na década de 1980, nosso país continua produzindo uma sociedade desigual e injusta e, hoje, a ditadura que se configura, se não mais a política, trata-se da econômica, tão ou mais perversa do que a anterior.

Percebemos hoje uma dinâmica escolar produtora não só de "alunos fracassados", mas também, conforme descreve Souza (2007), de "educadores fracassados": autoritarismo na dinâmica relacionada à implementação de projetos e atividades a serem desenvolvidas pelos professores; mudanças frequentes de educadores durante o ano letivo; convocações de última hora (cursos, oficinas, reuniões fora da unidade escolar são realizados sem planejamento prévio); baixos salários (obrigando os professores a terem até três jornadas de trabalho por dia - os professores entrevistados em nossa pesquisa têm uma carga horária semanal mínima de 50 horas de aula).

Nosso projeto de pesquisa/extensão tem nos revelado um quadro que parece nosso velho conhecido, já meio amarelado pelo tempo. Concepções que insistem em definir o "problema do fracasso escolar" como do próprio aluno, como se fosse criado por ele mesmo. Podemos dizer que não há nada de particularmente novo nesse quadro, vários estudos já o descreveram e o perigo é justamente esse, deixarmos de nos questionar por isso. Esse quadro não foi pintado pela natureza, ele vem sendo delineado ao longo da História por concepções e políticas que insistem, conforme nos aponta Bauman (2008), no "abandono do indivíduo a uma luta solitária para a qual a maioria de nós não conta com os recursos necessários para executá-la sozinho" (p. 13).

E foi essa realidade que nos levou a elaborar e oferecer uma disciplina que se propõe a estudar a obra de Maria Helena Souza Patto. Ela vem há décadas nos revelando que o liberalismo vestido com novas etiquetas continua sendo a ideologia política da burguesia. Para nós, psicólogos e educadores, outra grande contribuição dessa obra é nos mostrar, a todo instante, que, quanto mais insistimos em entender o subjetivo no contexto escolar, mais nos aproximamos das relações materiais de produção e da política, aspectos muitas vezes renegados por teóricos desse contexto. 
Intitulada como"A Produção do Fracasso Escolar na Obra de Maria Helena Souza Patto" e tendo como principal objetivo compreender o"Fracasso Escolar" a partir da obra da autora, nossa disciplina teve sua ementa constituída com o seguinte enfoque: $O$ objeto de estudo "fracasso escolar"na produção científica de Maria Helena Souza Patto. Raízes históricas das concepções sobre o fracasso escolar. O modo capitalista de pensar a escola no contexto mundial e brasileiro. A pesquisa no contexto do fracasso escolares: a crítica do conhecimento que faz do sujeito um objeto. As práticas diagnósticas realizadas por psicólogos no contexto escolar.

Um dos impasses produzidos durante a elaboração da disciplina foi a escolha da bibliografia a ser recomendada, devido à amplitude e riqueza da obra. Com uma carga horária semestral de 60 horas, optamos por organizar nossa disciplina por meio de um levantamento que nos permitiu constituir seis eixos que consideramos centrais e que perpassam toda a obra estudada e em que se apresentam conclusões que são essenciais no entendimento do que a autora, de forma inaugural, convencionou chamar de "fracasso escolar".

\section{Eixos estruturantes da disciplina}

Gostaríamos de deixar claro que a estrutura da disciplina aqui apresentada não alimentou uma discussão que versava sobre cada uma dessas temáticas de forma estanque. Não se trata aqui de pensar esses eixos separadamente. Todos os conceitos discutidos fazem parte de uma rede e não sabemos delimitar onde cada um deles começa e onde termina. Acreditamos que todos se entrelaçam na obra estudada. Essa construção teve apenas um propósito didático e faz parte de interesses e compreensões que nosso grupo desenvolveu a partir do estudo da obra de Maria Helena Souza Patto. Faz-se importante esclarecer aqui que em momento algum de sua obra a autora faz menção a eixos estruturantes.

Abaixo apresentaremos algumas notas sobre os eixos delimitados.

\section{1 - Concepções de Fracasso Escolar.}

Angelucci, Kalmus, Paparelli e Patto (2004) desenvolvem estudo que demonstra que a pesquisa educacional no Brasil ainda vem concebendo o fracasso escolar como fenômeno exclusivamente individual. Além dessa concepção, há ainda alta incidência de estudos que responsabilizam ora o aluno ora o professor e propõem soluções predominantemente técnicas para acabar com o fracasso. As suas principais críticas recaem sobre pesquisas que insistem em conceber o fracasso escolar a partir de três vertentes: a) como problema psíquico (a culpabilização acaba nas crianças e em seus pais); b) o fracasso escolar como um problema técnico 
do professor (culpabilização dos professores); c) o fracasso escolar relacionado à instituição escola.

Em sua obra, além das críticas às três vertentes acima relacionadas, constrói uma concepção em que o fenômeno é apresentado de forma complexa, sendo analisado a partir do Materialismo Histórico.

Partindo do modo materialista histórico de pensar esta relação é que afirmamos a necessidade de conhecer, pelo menos em seus aspectos fundamentais, a realidade social na qual se engendrou uma determinada versão sobre as diferenças de rendimento escolar existentes entre as crianças de diferentes origens sociais. (Patto, 1999a, pp. 27-28)

Sua consciência da importância de romper com a concepção tradicionalmente instituída produz uma contribuição inigualável com um marco nos estudos na área, seu livro $A$ produção do fracasso escolar: histórias de submissão e rebeldia (Patto, 1999), bibliografia básica em nossa disciplina.

Ainda para discutir outros aspectos do eixo aqui apresentado, fez parte de nossa bibliografia: 1) Patto, M. H. S. (1999b). Estado, ciência e política na Primeira República: a desqualificação dos pobres. Estudos Avançados, 13(35). Recuperado em 25 de outubro de 2010, da SciELO (Scientific Electronic Library OnLine): http://www.scielo.br; e 2) Angelucci, C. B., Kalmus, J., Paparelli, R., \& Patto, M. H. S. (2004). O estado da arte da pesquisa sobre o fracasso escolar (1991-2002): um estudo introdutório. Educação e Pesquisa, 30(1), 51-72. Recuperado em 25 de outubro de 2010, da SciELO (Scientific Electronic Library OnLine): http:/ /www.scielo.br.

\section{2 - As práticas diagnósticas realizadas por profissionais psicólogos no contexto escolar.}

Pesquisas já mostraram à exaustão a precariedade do processo e do produto de práticas diagnósticas realizadas por profissionais psicólogos: nos arquivos escolares são muitos os laudos sobre crianças que não conseguem se escolarizar (numa escola pública sabidamente falida, diga-se de passagem) que culpam a vítima com verdadeiros disparates:"criança com personalidade primitiva"; "o aluno apresenta dificuldades com a realidade do meio, com predomínio da vida instintiva"; ...Asneiras que seriam cômicas se não fossem trágicas, dada a capacidade que têm de estigmatizar e de justificar desigualdades sociais ao reduzi-las a deficiências individuais. Ou seja, a maioria dos psicólogos acredita, porque há concepções da própria Psicologia que estão fundadas nesta crença, que estão numa sociedade de oportunidades sociais iguais e de capacidades individuais diferentes: há aptos e inaptos, capazes e incapazes, superiores e inferiores - em resumo, vencedores e perdedores. (Mello \& Patto, 2008, p. 592) 
A crítica aos cursos de formação de psicólogos, aspecto central da discussão sobre suas práticas, não é mais branda:

\begin{abstract}
Sem o entendimento rigoroso e bem fundamentado do que se passa na subjetividade e nas relações intersubjetivas numa sociedade concreta, e sem a consciência da imensa responsabilidade dessas práticas, esses profissionais podem lesar direitos fundamentais das pessoas e, no limite, colaborar para a negação de seu direito à vida. Um psicólogo que não adquirir a capacidade de pensar o próprio pensamento da ciência que pratica - ou seja, de refletir sobre a dimensão epistemológica e ética do conhecimento que ela produz certamente somará, insciente, com o preconceito delirante, a opressão, o genocídio e a tortura. (Mello \& Patto, 2008, p. 594)
\end{abstract}

Assumindo uma postura de questionamento e crítica perante o conhecimento psicológico estabelecido e suas práticas, ela impõe a necessidade dos cursos de Psicologia incluírem em sua formação disciplinas que se aprofundem na história, em busca de suas origens, de seus pressupostos epistemológicos e de seus compromissos.

Com o propósito de compreender esse eixo, incluímos em nossa disciplina a seguinte bibliografia básica: 1) Patto, M.H.S.(1999a). A produção do fracasso escolar: histórias de submissão e rebeldia (4a ed.). São Paulo: Casa do Psicólogo; e 2) Patto, M. H. S. (2003). O que a história pode dizer sobre a profissão do psicólogo: a relação Psicologia-Educação. In A. M. B. Bock (Org.) Psicologia e compromisso social (pp. 29-35). São Paulo: Cortez.

3 - O estudo da história crítica da Psicologia em sua relação com a Pedagogia nas sociedades industriais capitalistas.

Seu estudo constante e aprofundado da história denota a importância e relevância dada à necessidade de sempre "ir à raiz dos conceitos". Ela insiste na necessidade de considerarmos a história para que possamos entender a situação atual do "fracasso escolar". Seus textos voltados para esse objetivo, além de nos levarem a entender o contexto atual, são uma denúncia do descaso com que a educação pública no Brasil vem sendo tratada ao longo de sua trajetória. Enfatiza a importância de estudos que não desprezem a história política, social, econômica e cultural do contexto onde a psicologia foi constituída.

Ir à raiz de conceitos, sistemas de conhecimento e métodos da psicologia significa esquadrinhar (criticamente) as teorias e práticas atuais dos psicólogos e alertá-los do aprisionamento da especialização; das determinações políticas da racionalidade que preside os seus pensares e fazeres; de sua dimensão histórica; da amnésia da gênese que os assola; de suas concepções naturalizadas de homem e de sociedade; de sua ação feita de esquecimentos da "instrumentação desmemoriada da ciência" - tudo isso para pensar os compromis- 
sos que a engendram, dos quais ela tem se mostrado insciente. Escrever a história da psicologia é, assim, uma atitude política, é comprometer-se com a dimensão ética dessa ciência e profissão. (Patto, 2000a, p. 88)

Entre vários fatores que ressaltam a relevância do estudo da história, ela insiste na necessidade da busca do entendimento do lugar que a Psicologia ocupou junto à Pedagogia e que ambas ocupam no cenário da história brasileira. Reafirma que só um minucioso estudo histórico poderá contribuir para a formação de profissionais críticos.

Nossa bibliografia básica para o eixo foi composta por: 1) Patto, $M$. H. S. (1999a). A produção do fracasso escolar: histórias de submissão e rebeldia. São Paulo: Casa do Psicólogo; 2) Patto, M. H. S. (1999b). Estado, ciência e política na Primeira República: a desqualificação dos pobres. Estudos Avançados, 13(35). Recuperado em 25 de outubro de 2010, da SciELO (Scientific Electronic Library OnLine):http://www.scielo.br;3) Patto, M.H.S. (2007).“Escolas cheias, cadeias vazias” Nota sobre as raízes ideológicas do pensamento educacional brasileiro. Estudos Avançados, 21(61). Recuperado em 01 de outubro de 2010, da SciELO (Scientific Electronic Library OnLine): http://www.scielo.br; e 4) Patto, M. H. S. (Org.). (2009). A cidadania negada: políticas públicas e formas de viver. São Paulo: Casa do Psicólogo.

\section{4 - Concepções acerca da patologia e da subjetividade.}

Normal é quem trabalha e obedece. Normal é quem não protesta, não reivindica e colabora com a ordem estabelecida. Tudo que se afaste disso é rotulado como patologia. Por quem? Por cientistas, sobretudo juristas, médicos (higienistas, psiquiatras, pediatras) e educadores, entre os quais estavam os primeiros porta-vozes dos conhecimentos produzidos pela Psicologia. (Patto, 2003, p. 32)

É desse lugar que a autora faz uma denúncia das consequências da patologização biopsíquica dos pobres e de como essas concepções tiveram como propósito responsabilizá-los por dificuldades que estão associadas a políticas educacionais que sempre insistiram em não vê-los como cidadãos.

Ao desconsiderarem que tudo o que é humano só pode ser entendido se remetido ao âmbito das relações de produção - pois este é o lugar da (des) humanidade inaugural -, estas concepções ignoram que, numa sociedade dividida, as relações sociais são marcadas por tensões que movem as produções culturais; ao afirmarem que individualismo e indiferença pelo outro são disposições neuropsíquicas que contrariam um momento econômico e social que exige cooperação e envolvimento, ignoram a relação entre subjetividade e estrutura social. (Patto, 2000b, pp. 172-173) 
A patologização do fracasso escolar produz facilmente a medicalização das dificuldades de escolarização das crianças das classes populares. Procedimentos de profissionais que insistem em tratar o problema a partir da desconsideração de sua relação com a estrutura social.

E mesmo reconhecendo que o recorte da Psicologia esteja no individual ou subjetivo, ela não pode perder de vista as dimensões histórica, econômica, social, cultural e política da vida dos homens. Enfatiza que a Filosofia é imprescindível como condição de existência da reflexão teórica.

Os textos que nortearam essa discussão em nossa disciplina foram: 1) Patto, M.H.S. (1999a). A produção do fracasso escolar: histórias de submissão e rebeldia (4a ed.). São Paulo: Casa do Psicólogo; 2) Patto, M. H. S. (2003). O que a história pode dizer sobre a profissão do psicólogo: a relação psicologia-educação. In A. M. B. Bock (Org.). Psicologia e compromisso social (pp. 29-35). São Paulo: Cortez; e 3) Patto, M. H. S., \& Pereira, J. A. F. (2007). Pensamento cruel - humanidades e ciências humanas: há lugar para a psicologia? São Paulo: Casa do Psicólogo.

5 - A crítica do conhecimento que faz do sujeito um objeto.

Coloca em destaque ao longo de sua obra a necessidade de pensarmos a produção do conhecimento em Psicologia e Educação. Por discutir minuciosamente esse tema, toca num ponto central da produção do conhecimento nos Programas de Pós-Graduação em Educação: o lugar dos orientadores na definição dos objetos de estudo de dissertações e teses de modo a desenvolverem pesquisas que contemplem questões relevantes levantadas, mas não respondidas, em pesquisas anteriores. Sua obra nos fez pensar criticamente nossas pesquisas e interesses históricos e sociais que as norteiam.

Só assim, o campo da pesquisa educacional poderá ser mais do que um conjunto de pesquisas que não somam, ou somam pouco e, por isso, acabam trazendo contribuição limitada ao avanço do entendimento de questões candentes postas pela realidade escolar brasileira, de modo a colaborar, de fato, com a construção histórica da escola pública democrática. (Angelucci et al., 2004, p. 65)

A produção do conhecimento que ela defende busca, segundo Patto (2009), "andar na direção contrária de uma metodologia que, em nome de ilusória neutralidade dos resultados, faz do sujeito pesquisado um objeto, e separa-o do suposto sujeito do conhecimento - o pesquisador" (p. 18).

A disciplina construiu um espaço de discussão sobre as concepções metodológicas que norteiam nossas pesquisas e, a partir de conceitos com bases marxistas, levou-nos a um aprofundamento de aspectos essenciais e indissociáveis, como Ética e Ciência. 
Nessa linha, alguns de seus textos nos conduziram a questionamentos sobre o conhecimento que produzimos e a necessidade de busca de suas origens, de seus pressupostos epistemológicos e de seus compromissos. Entre esses textos, podemos enumerar: 1) Angelucci, C.B., Kalmus, J., Paparelli, R., \& Patto, M. H.S. (2004). O estado da arte da pesquisa sobre o fracasso escolar (1991-2002): um estudo introdutório. Educação e Pesquisa, 30(1), 51-72. Recuperado em 25 de outubro de 2010, da SciELO (Scientific Electronic Library OnLine): http://www.scielo.br; 2) Patto, M. H. S., \& Pereira, J. A. F. (2007). Pensamento cruel - humanidades e ciências humanas: há lugar para a psicologia? São Paulo: Casa do Psicólogo; e 3) Patto, M. H. S. (Org.). (2009). A cidadania negada: políticas públicas e formas de viver. São Paulo: Casa do Psicólogo.

\section{6 - A resistência pela via da postura política de insistência na recusa do estabelecido.}

A postura profissional que defende e realiza, principalmente em suas pesquisas, em que, dando a palavra aos sujeitos pesquisados, em sua maioria sujeitos que tiveram ao longo de sua história seus direitos sequestrados, visa assumidamente uma trajetória de insistência na recusa do estabelecido. Em sua obra sempre aponta possibilidades de resistência a partir de inúmeros caminhos.

A resistência à mediocridade de uma época pode tomar muitas formas. Podese recusá-la em parte, contrariando alguns de seus valores mais caros, como o diploma, o casamento, a poupança; pode-se recusá-la in totum, pela escolha de vida vagabunda; pode-se partir para a ação política, e participar da luta armada. Mas se pode também rejeitar uma sociedade pela realização das capacidades e dos valores de conteúdo positivo dos quais ela é mais falta. Cézanne e os melhores artistas de sua época exerceram um modo todo especial de dissidência: realizaram o espírito na mais materialista das civilizações. Fizeram-no na acepção mais alta da expressão: num tempo inebriado pelas valsas vienenses e operetas de Offenbach, empenharam-se num projeto de renovação estética, cuja realização exigia nada menos do que uma vida inteira dedicada ao trabalho enquanto atividade vital difícil, mas generosa, na qual "o homem é livre diante de seu produto e constrói em conformidade com as leis do belo".(Patto, 2000, p. 45)

Hoje, após nosso reencontro com a obra de Maria Helena Souza Patto, percebemos que ela, também com seu trabalho incansável, produto de uma vida inteira dedicada à formação de psicólogos, mestres e doutores, nos ensina como ninguém a resistir. Resistir hoje, época em que a mediocridade atinge níveis inimagináveis e muitas vezes toma o espaço acadêmico. Uma resistência pela via da produção de um conhecimento comprometido com a educação escolar das classes populares no país. Nossos estudos sobre a obra de Maria Helena Souza Patto, entre tantas 
reflexões, nos permitiram compreender que a produção de conhecimento sobre o tema "fracasso escolar" é feita de "continuidade e descontinuidade"e que muitas imagens já nos foram apresentadas. Mas sabemos da importância de continuarmos buscando novos ângulos para entendermos melhor a questão. Entretanto, o desafio está aí, ver novos ângulos de um mesmo objeto. Assim, vamos em busca de uma nova abertura que nos permita, segundo Patto (2009), "ver ou ouvir o inédito sob a carapaça do costumeiro" (p. 20). Um desafio que nos lança e que, como poucos, realiza permanentemente.

O pensamento da autora contribui para que possamos romper os limites da denúncia e da crítica improdutiva. Isso porque se, por um lado, revela a dominação dos "cativeiros" a que estamos todos historicamente submetidos, por outro, nos apresenta as formas possíveis de resistência a ela, apesar de seus múltiplos tentáculos. Sua contribuição é fundamental para quem deseja pensar o contexto em que vive de uma forma crítica e que almeja contribuir com a resistência às armadilhas da mediocridade que toma conta da sociedade.

\section{Desdobramentos produzidos pela disciplina}

Como relatamos anteriormente, essa disciplina foi oferecida no semestre letivo 2009/2 (será ofertada novamente no semestre letivo de 2011/1) e, diante de uma turma composta por alunos com diferentes objetos de pesquisa e formações (psicologia, pedagogia, filosofia, história etc.), outros interesses e reflexões foram surgindo e, a partir dos debates gerados, grupos de estudos foram sendo formados e alguns autores encontrados na obra de Maria Helena Souza Patto começaram a ser introduzidos nas dissertações e teses dos alunos, entre eles: Agnes Heller; Eric Hobsbawm; Pierre Bourdieu; Theodor W. Adorno; Antonio Gramsci; Karl Marx; entre outros.

A disciplina incitou nos alunos, e em todos nós, a necessidade de pensar as teorias que buscam explicar o "fracasso escolar" ainda tão presente hoje na realidade educacional brasileira. Pensar com o propósito de uma reflexão comprometida em denunciar a desumanização encontrada nas escolas públicas brasileiras. Essas reflexões trouxeram inúmeras contribuições para a psicologia e áreas afins. Entre elas, uma que consideramos fundamental é nos revelar que, quanto mais buscarmos compreender a subjetividade no contexto escolar, mais nos aproximamos das questões sociais e políticas. Denuncia com isso que não há mais espaço para teorias que buscam a culpabilização dos alunos pela via da patologização dos problemas escolares, que vêm se configurando ao longo de nossa história em uma insistente desconsideração das múltiplas determinações do contexto da aprendizagem. Ou, ainda, para discursos 
que apontam para uma culpabilização das relações familiares, explicações que acabam apontando que os determinantes dos problemas de aprendizagem da criança estão relacionados a conflitos familiares. Explicações que tendem para uma medicalização do problema, transformando questões complexas, muitas vezes sociais, em problemas médicos, relacionando-os exclusivamente ao indivíduo em particular.

Suas contribuições teóricas nunca foram tão atuais. Para isso basta analisarmos os dados apresentados hoje pelas avaliações produzidas pelas políticas de educação. As denúncias de Maria Helena Souza Patto ficam evidentemente ilustradas nos resultados apresentados pelo Índice de Desenvolvimento da Educação Básica (IDEB) ${ }^{1}$ (2009/2010). Eles demonstram o descaso com que na atualidade as políticas públicas de educação vêm sendo tratadas. Índices que revelam que a permanência dos alunos por mais tempo hoje nas escolas, necessariamente não implica em aprendizagem e que aprovação não significa, portanto, aquisição de conhecimento. A estratégia neoliberal atual parece então resumir a qualidade da escola a números de alunos matriculados e aprovados, mas a qualidade da educação pouco é questionada. Essas políticas trazem um grave problema: mascaram o"fracasso escolar".

A "progressão continuada" é a mais perfeita realização desta política sob a alegação convincente dos males causados pelas reprovações, empurram-se agora, o mais rápido possível, os alunos pelas oito séries do ensino fundamental, não importa o nível de apropriação dos conteúdos curriculares. (Patto, 2009, p. 186)

Por isso, resistir a essas políticas e aos discursos que patologizam os problemas de aprendizagem é a tônica da obra de Maria Helena Souza Patto e ela produz a possibilidade de sempre estarmos questionando o real contexto do ensino nas escolas públicas brasileiras.

Buscamos, ao estudar sua obra, enfatizar a importância da discussão sobre o "fracasso escolar", termo cunhado por ela a partir de uma construção teórica que faz para explicar o mau desempenho das crianças pobres principalmente nas séries iniciais da escolarização. Além de buscarmos uma compreensão teórica também procuramos subsídios para nossa intervenção nas escolas municipais de Vitória, em nosso projeto de extensão que visa uma orientação à queixa escolar, a partir do que a autora instituiu com a sua discussão.

10 Índice de Desenvolvimento da Educação Básica (IDEB) é um indicador que se baseia no desempenho do aluno em avaliações do Instituto Nacional de Estudos e Pesquisas Educacionais Anísio Teixeira (INEP) e em taxas de aprovação. 0 índice é medido a cada dois anos e o objetivo é que o país, a partir do alcance das metas municipais e estaduais, tenha nota 6 em 2022 - correspondente à qualidade do ensino em países desenvolvidos. 0 IDEB de cada instituição é apresentado em uma escala de zero a dez pontos (http://portal.mec.gov.br). 
As discussões suscitadas pela disciplina trouxeram também, como produto, a elaboração de um projeto para o Programa Institucional de Bolsas de Iniciação Científica (PIBIC) da UFES, objetivando o desenvolvimento de pesquisas na graduação em Pedagogia e Psicologia, buscando diminuir o hiato ainda existente entre essas áreas do conhecimento no município de Vitória e na Universidade Federal do Espírito Santo. Hoje, além do projeto intitulado "Contribuições da obra de Maria Helena Souza Patto na compreensão do 'fracasso escolar' em escolas públicas do município de Vitória",está em pleno desenvolvimento a tese de doutorado intitulada "Desvelando o cotidiano de 'alunos que não aprendem na escola': um estudo de caso", ambos norteados pela obra da professora Maria Helena Souza Patto. Para ampliar ainda mais as influências dessa autora no contexto do PPGE, incluímos no processo de seleção do mestrado 2010/2011, na linha Diversidade e Práticas Educacionais Inclusivas, na bibliografia indicada para a prova de conhecimentos específicos, o livro: Patto, M.H.S.(2008). A produção do fracasso escolar: histórias de submissão e rebeldia. São Paulo: Casa do Psicólogo.

Esses são alguns dos desdobramentos produzidos pelo reencontro com a obra de Maria Helena Souza Patto. Sabemos que sua obra em plena construção continuará trazendo luz aos caminhos que traçamos para compreender nossa prática profissional e o contexto da educação brasileira.

É porque o tempo entre o nascer e o morrer é breve que, paradoxalmente, não pode haver pressa nas realizações. Para que o trabalho de criação resulte num produto de qualidade, é preciso deter-se, organizar-se, perseverar,"ordenar cada dia como se fosse uma vida". (Patto, 2000b, p. 47)

Em um tempo em que tudo parece tão superficial e descartável, sua obra resiste e com profundidade e consistência mantém uma inabalável postura de permanente crítica das mazelas da educação brasileira que pouco se alterou ao longo de sua história.

os tecnocratas dirão que pessoas assim não contribuem, pois "só criticam", fazendo de conta que não sabem que as críticas à política educacional resultam das próprias medidas oficiais, que têm como regra deixar intactos os problemas de fundo do sistema escolar brasileiro. (Patto, 2000, pp. 150-151)

Enfrentando os tecnocratas que historicamente, segundo Patto (2000b), promovem "mudanças educacionais cosméticas" e condenam a escola pública a um cotidiano dramático, sua obra muito contribui para que continuemos a buscar uma educação pública de qualidade que vem sendo negada ao longo da história brasileira. Pelos rumos que a política atual vem tomando, os acontecimentos acenam que podemos estar diante de "momentos perigosos da história", e nesses momentos, mais do que 
nunca, precisamos de sua obra e de uma intelectual, que como Maria Helena Souza Patto, continue resistindo incansavelmente em denunciar a barbárie atual.

\section{Notes on the contribution of Maria Helena Souza Patto's work on a postgraduate program in Education}

Abstract: This study aims at to present the formulation and implantation background of a discipline offered by the Postgraduate program in Education (PPGE) at the Federal University of Espírito Santo (UFES) since 2009, entitled "The Production of School Failure in Maria Helena Souza Patto's Work". The study aims to report the the contributions of this discipline and the author's work in training teachers and researchers who have as their object of study, school failure in public schools and Espirito Santo in Brazil. For this purpose, we present the context of PPGE, setting the course offered and how that work was being unveiled for the group of students (masters and doctorates), as well as the ramifications of the discipline in PPGE.

Keywords: Teacher education. School Failure. Postgraduate training. School Psychology.

\section{Notes sur la contribution de l'œuvre de Maria Helena Souza Patto dans un programme de spécialisation en Éducation}

Résumé: Le but de cet article est de présenter le parcours d'élaboration et d'implantation d'une discipline offerte, à partir de 2009, par le Programme de Spécialisation en Éducation (PPGE) de l'Université Fédérale de l'Espírito Santo (UFES), intitulée "La Production d'Échec Scolaire dans l'Oeuvre de Maria Helena Souza Patto" et de montrer la contribution de cette discipline et de l'oeuvre dudit auteur sur la formation de professeurs et de chercheurs qui ont, pour objet d'étude, l'échec scolaire dans les écoles publiques de l'État de l'Espírito Santo et même du Brésil. Avec ce but, nous présentons le contexte du PPGE, la configuration de la discipline offerte et comme l'oeuvre mentionnée ci-dessus a été dévoilée par le groupe d'étudiants (ceux qui préparent un mastère II et un doctorat) ainsi que les dédoublements de la discipline au PPGE.

Mots-clés: Formation de professeurs. Échec scolaire. Programme de Spécialisation. Psychologie scolaire. 


\section{Notas sobre la contribución de la obra de Maria Helena Souza Patto en un programa de posgrado en educación}

Resumen: El objetivo de este artículo es presentar la trayectoria de elaboración e implantación de una signatura ofrecida, a partir del año 2009, por el Programa de Posgrado en Educación (PPGE) de la Universidade Federal do Espírito Santo (UFES), llamada "La Producción del Fracaso Escolar en la Obra de Maria Helena Souza Patto" y relatar las contribuciones de esta signatura y de la obra del autora en la formación de profesores e investigadores que tienen como objetivo de estudio el "fracaso escolar" en escuelas públicas capixabas y brasileñas. Con ese propósito, presentamos el contexto del PPGE, la configuración de la signatura ofrecida y cómo el grupo de alumnos (de maestría y doctorado) descubrió dicha obra, así como los desdoblamientos de la signatura en el PPGE.

Palabras clave: Formación de professores.Fracaso escolar. Posgrado. Psicología escolar.

\section{Referências}

Angelucci, C. B., Kalmus, J., Paparelli, R., \& Patto, M. H.S. (2004). O estado da arte da pesquisa sobre o fracasso escolar (1991-2002): um estudo introdutório. Educação e Pesquisa, 30(1), 51-72. Recuperado em 25 de outubro de 2010, da SciELO (Scientific Electronic Library OnLine): http://www.scielo.br

Bauman, Z. (2008). A sociedade individualizada: vidas contadas e histórias vividas. Rio de Janeiro: Jorge Zahar.

Mello, S. L., \& Patto, M. H.S. (2008). Psicologia da violência ou violência da psicologia? Psicologia USP, 19(4), 591-594. Recuperado em 01 de outubro de 2010, da SciELO (Scientific Electronic Library OnLine): http://www.scielo.br

Patto, M. H. S. (1999a). A produção do fracasso escolar: histórias de submissão e rebeldia (4a ed.). São Paulo: Casa do Psicólogo.

Patto, M. H.S. (1999b). Estado, ciência e política na Primeira República: a desqualificação dos pobres. Estudos Avançados, 13(35). Recuperado em 25 de outubro de 2010, da SciELO (Scientific Electronic Library OnLine): http:// www.scielo.br

Patto, M. H. S. (2000a). Para escrever uma história da psicologia. In Seminário de Historiografia da Psicologia, 1 (pp. 81-96). São Paulo: GEHPAI/FAPESP. 
Patto, M. H. S. (2000b). Mutações do cativeiro: escritos de psicologia e política. São Paulo: Edusp.

Patto, M.H.S. (2003). O que a história pode dizer sobre a profissão do psicólogo:a relação Psicologia-Educação. In A. M. B. Bock (Org.), Psicologia e compromisso social (pp. 29-35). São Paulo: Cortez.

Patto, M.H.S. (2007a). Escolas cheias, cadeias vazias: nota sobre as raízes ideológicas do pensamento educacional brasileiro. Estudos Avançados, 21(61). Recuperado em 01 de outubro de 2010, da SciELO (Scientific Electronic Library OnLine): http://www.scielo.br

Patto, M.H. S., \& Pereira, J. A. F. (2007b). Pensamento cruel - humanidades e ciências humanas: há lugar para a psicologia? São Paulo: Casa do Psicólogo.

Patto, M. H. S. (Org.). (2009). A cidadania negada: políticas públicas e formas de viver. São Paulo: Casa do Psicólogo.

Souza, M. P. R. A. (2007). A queixa escolar na formação de psicólogos: desafios e perspectivas. In E. R. Tanamachi, M.Proença \& M. L. Rocha (Orgs.), Psicologia e educação: desafios teórico-práticos (pp. 105-141). São Paulo: Casa do Psicólogo. 
Elizabete Bassani, Doutoranda no Programa de Pós-Graduação em Educação da Universidade Federal do Espírito Santo. Endereço para correspondência: Av. Hugo Viola, 750, Jardim da Penha. Vitória, ES. Brasil. CEP: 29060-420, Endereço eletrônico: betebassani@ig.com.br

Hiran Pinel, Professor Doutor do Programa de Pós-Graduação em Educação da Universidade Federal do Espírito Santo. Endereço para correspondência:Rua Cyro Lopes Pereira, 993, Jardim da Penha.Vitória, ES. Brasil. CEP: 29060-020, Endereço eletrônico:hiranpinel@ig.com.br 